\title{
INDONESIAN TEACHERS CLASSROOM ASSESSMENT METHOD
}

\author{
Saefurrohman ${ }^{1}$, Ahmad $^{2}$ \\ \{ saefurrohman@ump.ac.id ${ }^{1}$, ahmadump@yahoo.co.id $\left.{ }^{2}\right\}$ \\ ${ }^{1,2}$ Universitas Muhammadiyah Purwokerto, Indonesia
}

\begin{abstract}
The aim of this study was to find out the Indonesian Teachers Classroom assessment method in helping their students to monitor their own learning, enhancing teaching and improve learning and measuring the level of students' achievement.To meet the goal of the study, survey design was adopted to gather descriptive and comparative data. Electronic survey questionnaire using e-surv free survey tool was built to get the data set. 200 secondary and high school teachers in central, west and east Java were sent e-questionnaire and 58 were returned.The study found that the assessment method that is most often used for once a month is an assessment portfolio with $50.94 \%$. The most used method for once a week is a filling gap test, and the method that is used most often for daily is short answer with $49.06 \%$. In addition, the majority of Indonesian Teacher used self assessment in helping their students to monitor their own learning. Moreover, performance assessment was the most highly used assessment in enhancing teaching and improve learning. Finally, multiple choice and essay test was the most common used of assessment method to measure the students learning outcome.
\end{abstract}

Keywords: Indonesian Teachers, Classroom Assessment, Method.

\section{Introduction}

Assessment is very important in the teaching and learning process in the classroom. A good assessment will give an idea of the actual conditions of life. Assessment is also one of the activities carried out to measure and assess the level of achievement and effectiveness of the learning process. Assessment is also used to determine the strengths and weaknesses that exist in the learning process.

A professional teacher must be able to master the types and methods of assessment that are appropriate for their students. The selection of the right method will have an impact on achieving the objectives of the assessment. Thus, the teacher must use a variety of assessment methods and techniques that are in accordance with the learning objectives and characteristics of the learning experience.

There are some assessment methods that can be used by teachers, among the assessment methods that are usually used by the teacher can be divided into two, traditional and alternative assessment. Traditional assessment usually relates to Traditional evaluation usually relates to written testing, such as multiple choice, matching, true/false, fill in the blank, etc. Traditional assessment such multiple choice and quizz is essential as it provides an overview of the learning of a student in a grade or rank form at a specific subject. 
Alternative assessment referred to as performance tests or authentic evaluations, are used to determine what students can and can not do. In other words, an alternative assessment measure implemented more skill than it measures understanding. Alternative assessment provides fresh methods to motivate and inspire learners to discover and utilize their own and the world around them..

\section{Research Methodology}

The purpose of this study was to explore teachers' classroom assessment method in Class. To meet this goal, survey design was adopted to gather descriptive and comparative data. Electronic survey questionnaire using e-surv free survey tool was built to get the data set. 200 secondary and high school teachers in central, west and east Java were sent equestionnaire and 58 were returned. Descriptive analyses including frequencies, percentages, and means were used to summarize the distribution of the data, while thematic data analysis using Creswell model was used in analyzing all the qualitative data.

\section{Result and Discussion}

The result will give an overview on the frequent of classroom assessment method conducted by teachers in their teaching and learning Process. Assessment method deals with the purpose of the assessment will be also discuss he.

The of the teachers frequency in using classroom assessment methods can be seen in following table :

Table 1. the frequency of Classroom assessment methods used by Teachers

\begin{tabular}{|ll|l|l|l|l|}
\hline \multicolumn{2}{|c|}{ Classroom Assessment method } & \multicolumn{1}{|c|}{ Never } & Montly & Weekly & Daily \\
\hline 1. & True/False Test & $11.32 \%$ & $49.06 \%$ & $22.64 \%$ & $16.98 \%$ \\
\hline 2. $\quad$ Multiple Choice Test & $1.89 \%$ & $41.51 \%$ & $47.17 \%$ & $9.43 \%$ \\
\hline 3. & Filling Gap Test & $11.32 \%$ & $32.08 \%$ & $45.28 \%$ & $11.32 \%$ \\
\hline 4. $\quad$ Short Answer & $1.89 \%$ & $11.32 \%$ & $37.74 \%$ & $49.06 \%$ \\
\hline 5. $\quad$ Matching & $5.66 \%$ & $26.42 \%$ & $47.17 \%$ & $20.75 \%$ \\
\hline 6. $\quad$ Essay & $0 \%$ & $33.96 \%$ & $33.96 \%$ & $32.08 \%$ \\
\hline 7. $\quad$ Performance Assessment & $1.89 \%$ & $43.40 \%$ & $33.96 \%$ & $20.75 \%$ \\
\hline 8. $\quad$ Portfolio Assessment & $24.53 \%$ & $64.15 \%$ & $7.55 \%$ & $3.77 \%$ \\
\hline 9. Project Based Assessment & $30.19 \%$ & $50.94 \%$ & $16.98 \%$ & $1.89 \%$ \\
\hline 10. Self Assessment & $7.55 \%$ & $39.62 \%$ & $35.85 \%$ & $16.98 \%$ \\
\hline 11. Peer Assessment & $18.87 \%$ & $37.74 \%$ & $28.30 \%$ & $15.09 \%$ \\
\hline 12. Learning log & $50.94 \%$ & $30.19 \%$ & $13.21 \%$ & $5.66 \%$ \\
\hline 13. Journal Assessment & $32.08 \%$ & $49.06 \%$ & $11.32 \%$ & $7.55 \%$ \\
\hline
\end{tabular}

From the data above, it can be seen that Project based learning and Journal assessment (30.19\% and $32.08 \%)$ are assessment methods that are rarely used by teachers, while the assessment method that is most often used for once a month is an assessment portfolio with $50.94 \%$. The most used method for once a week is a filling gap test, and the method that is used most often for daily is short answer with $49.06 \%$ 
In addition to this, as can be seen in table 2 ,the method used to help students monitor their learning The results obtained from the survey mention if the teacher uses self assessment in measuring student learning outcomes, while learning log is a method that is rarely used.

Table 2. The percentage of asessment method to monitor students learning

\begin{tabular}{|l|l|r|}
\hline \multicolumn{1}{|c|}{ Assessment method } & & $\mathbf{( \% )}$ \\
\hline Self Assessment & & 38.95 \\
\hline Peer Assessment & & 24.21 \\
\hline Learning Log & & 6.32 \\
\hline Rective Journal & & 15.79 \\
\hline Portfolio & & 14.74 \\
\hline
\end{tabular}

As can be seen in table 3 below, teacher uses performance assessment to enhance teaching and improve learning, while learning log is a method that is rarely used by teacher

Table 3. Assessment methods to enhance teaching and improve learning

\begin{tabular}{|l|l|c|}
\hline Assessment Method & & $\mathbf{( \% )}$ \\
\hline Performance Assessment & & 30.16 \\
\hline Portfolio Assessment & & 10.32 \\
\hline Project Based Assessment & & 16.67 \\
\hline Self Assessment & & 16.67 \\
\hline Peer Assessment & & 13.49 \\
\hline Journal & & 12.70 \\
\hline
\end{tabular}

Table 4 shows the teachers assessment methods in measuring the students learning outcome. The result shows that multiple choice and essay test are the most common uses, while journal was the least popular one to measure the students learning outcome

Table 4. Assessment method to measure learning outcome

\begin{tabular}{|l|r|r|}
\hline Assessment Method & & Response (\%) \\
\hline True/ False Test & & 10.14 \\
\hline Multiple choice Test & & 15.46 \\
\hline Gap Filling Test & & 9.18 \\
\hline Short Answer & & 14.98 \\
\hline Essay & & 16.43 \\
\hline Performace Assessment & & 13.53 \\
\hline Project Based Assessment & & 8.70 \\
\hline Portfolio Assessment & & 7.25 \\
\hline Journal & & 4.35 \\
\hline
\end{tabular}




\section{Conclusion}

The assessment method that is most often used for once a month is an assessment portfolio with $50.94 \%$. The most used method for once a week is a filling gap test, and the method that is used most often for daily is short answer with $49.06 \%$. In addition, the majority of Indonesian Teacher used self-assessment in helping their students to monitor their own learning. Moreover, performance assessment was the most highly used assessment in enhancing teaching and improve learning. Finally, multiple choice and essay test was the most common used of assessment method to measure the students learning outcome

\section{References}

[1] Black, P., \& Wiliam, D. (1998). Assessment and Classroom Learning. Assessment in Education: Principles, Policy \& Practice, 5, 7-74. Retrieved from http://doi.org/fpnss4.

[2] Black, P., \& Wiliam, D. (2005). Lessons from around the world: How policies, politics and cultures constrain and afford assessment practices. The Curriculum Journal. 16(2),249-261.

[3] Black, P., Harrison, C., Lee, C., Marshall, B., \& Wiliam, D. (2004). Working Inside the Black Box: Assessment for Learning in the Classroom. Phi Delta Kappan, 86 (1): 9-21.

[4] Brualdi, A. (1998). Implementing Performance Assessment In The Classroom. Practical Assessment, Research \& Evaluation, 6(2). Available online: http://ericae.net/pare/getvn.asp?v=6\&n=2.

[5] Chan, Yu-Ching. (2014). Elementary School EFL Teachers' Beliefs and Practices of Multiple Assessments. Reflections on English Language Teaching, Vol. 7, No. 1, pp. 37-62.

[6] Cheng, Liying., Rogers, Todd., \& Hu, Huiqin. (2004). ESL/EFL Instructors' Classroom Assessment Practices: Purposes, Methods, and Procedures Language Testing 2004 21: 360. DOI: 10.1191/0265532204lt288oa. http://ltj.sagepub.com/content/21/3/360.

[7] Cheng, X. Y. (2008). Attitudes towards mediation among EFL teachers in China and constraints in their classroom practices. Kaifeng: Henan University Press.

[8] Earl, L. (2003). Assessment as Learning: Using Classroom Assessment to Maximize Student Learning. Thousand Oaks, CA: Corwin Press.

[9] Earl, L. and Katz, S. (2006). Leading in a Data Rich World: Harnessing Data for School Improvement. Thousand Oaks Corwin Press.

[10] Stiggings, R. (2004). New Assessment Beliefs for a New School. Phi Delta Kappan, 86, 22-27.

[11] Weegar, M. \& Pacis, D. (2012). A Comparison of Two Theories of Learning -- Behaviorism and Constructivism as applied to Face-to-Face and Online Learning. Proceedings E-Leader Conference, Manila 2012

[12] Western and Northern Canadian Protocol for Collaboration in Education (WNCP). (2006). Rethinking Classroom Assessment with Purpose in Mind: Assessment for Learning, Assessment as Learning, Assessment of Learning. Retrieved July 11, 2006, from http://www.wncp.ca/assessment/rethink.pdf 